О.І. Тимочко ${ }^{1}$, Г.В. Дубовик ${ }^{2}$, В.С. Мажаров ${ }^{3}$

${ }^{1}$ Харківський начіональний університет Повітряних Сил ім. І. Кожедуба, Харків

${ }^{2}$ Національний університет оборони України ім. I. Черняховського, Київ

${ }^{3}$ Льотна академія Наџіонального авіаџійного університету, Кропивницький

\title{
МЕТОД ФОРМАЛІЗАЦІї ДАНИХ ПРИ ВИРІШЕННІ ЗАДАЧ РОЗПІЗНАВАННЯ ПОВІТРЯНИХ ОБ'ЄКТІВ
}

\begin{abstract}
В роботі розроблена методика формалізації структур даних ознак повітряних об'єктів яка враховує характеристики точності і достовірності джерел інформації з нестохастичною невизначеністю і рекурентними правилами узагальнення оцінок значень ознак при багаторазовому спостереженні повітряних об’єктів. В основу розробленої методики були покладені методи формалізації процесу розпізнавання, оцінки ступеня істинності різнорідних ознак, об'єднання незалежних результатів розпізнавання, пошуку рішень про класи розпізнаваних повітряних об'єктів з урахуванням неповноти і надмірності даних про ознаки. Розроблений метод формалізації прочесу розпізнавання повітряних об'єктів на основі описів класів різнорідними ознаками, відрізняється від відомих використанням ієрархічної функціональної мережі. Удосконалення методу об'єднання незалежних результатів розпізнавання на основі правила Демпстера полягає в попередньому перетворенні одного з неузгоджених розподілів можливостей класів алфавіту в розподіл ймовірностей. Це дозволяє проводити коректне об'єднання неузгоджених розподілів можливостей класів алфавіту $з$ використанням правила Демпстера. Проведено дослідження застосовності розробленого правила при об'єднанні неузгоджених розподілів ймовірностей класів алфавіту. Розроблений метод пошуку рішень про класи розпізнаваних об'єктів на графі функиіональної мережі відрізняється від відомих розробленим способом отримання інтервальної очінки ступеня істинності класів в умовах відсутності даних щзодо окремих ознак повітряних об'єктів і запропонованим евристичним правилом, щзо дозволяє скоротити розмірність безлічі вершин мережі, які перебираються при пошуку рішення про клас повітряних об'єктів. Метод дозволяє проводити пошук рішень про класи повітряних об'єктів в умовах неповноти і надмірності даних про ознаки.
\end{abstract}

Ключові слова: формалізація даних, ознаки повітряних об’єктів, розпізнавання, неповнота даних.

\section{Вступ}

Постановка проблеми. Впровадження в автоматизовані системи управління підсистем інформаційного забезпечення процесу підтримки прийняття рішень, а також застосування інтелектуальних інформаційних технологій для реалізації автоматизованих підсистем рішення окремих творчих завдань, вимагає застосування методів подання і використання знань для оцінки даних про повітряну обстановку, як основи для вироблення рішень в таких системах.

Використання знань дозволяє знаходити рішення складних, відкритих завдань [1], використовувати евристичні методи вирішення складних завдань, а також приймати рішення в умовах неповноти і невизначеності інформації про стан об’ єктів, або зовнішнього середовища.

Однією з задач розробки таких інтелектуальних систем $\epsilon$ необхідність представлення та обробки великої кількості даних різної природи та структури. Особливо актуальною ця задача стає для систем розпізнавання повітряних об'єктів, яка дозволяє провести ідентифікацію самих об'єктів, та отримати додаткову інформацію в ході оцінки повітряної обстановки та вироблення рішень в різних умовах.
Для систем підтримки прийняття рішення (СППР), що використовуються в системах управління військового призначення, актуальним $є$ вирішення завдання розпізнавання в реальному масштабі часу, з метою підвищення якості вирішення завдань: управління інформаційними моделями (IM) повітряної обстановки (BO), оперативного корегування планів ведення бойових дій, своєчасного реагування на зміни в обстановці та ін, що потребує вирішення завдання представлення та обробки великих обсягів даних, що динамічно змінюються.

Аналіз останніх досліджень і публікацій. Дослідження 3 питань спільної обробки різнорідної ознакової інформації в інформаційних системах різного призначення показують, що один 3 можливих підходів до математичного опису даних, що характеризуються високим рівнем невизначеності стохастичного і нестохастичного виду, заснований на результатах теорії мір.

При цьому широко використовується клас нечітких мір, вільних від ряду обмежень ймовірнісних мір. До таких мір належать міри можливості, необхідності, базисної ймовірності [1-2].

При формалізації даних про значеннях якісних ознак, що надійшли у вигляді природно-мовних по- 
відомлень, також використовуються знання експертів, що характеризують неточність оцінок, представлені з використанням лінгвістичної ступеня впевненості у вигляді нечіткої множини [3-4].

Дані, що надходять від конкретного оператора, спостерігача, в залежності від рівня його підготовки, можуть не відповідати знанням експертів про властиві йому неточності оцінок [5].

Мета статті. Метою дослідження $є$ розробка методики формалізації структур даних ознак повітряних об'єктів яка враховує характеристики точності і достовірності джерел інформації з нестохастичною невизначеністю і рекурентними правилами узагальнення оцінок значень ознак при багаторазовому спостереженні повітряних об’єктів.

\section{Виклад основного матеріалу}

\section{1. Формалізація оцінок значень ознак 3 нестохастичною невизначеністю}

Нехай кожній оцінці $\hat{x}$ значення ознаки, що надійшла від джерела інформації, відповідає деяка підмножина $A_{j}$ множини $A$ всіх його допустимих значень. В якості міри неточності інформації від розглянутих джерел будемо використовувати нечіткі міри, що задовольняють властивостям обмеженості і монотонності.

Згідно властивостей обмеженості нечітких мір, при повній довірі до інформації від джерел розглянутого типу, неточність їх оцінок повинна збігатися 3 неточністю, обумовленої експертними знаннями. При абсолютній недовірі значення міри неточності має дорівнювати нулю.

Якщо оцінювати рівень кваліфікації оператора $U$ по $N$-бальною шкалою $U=1, \ldots, N$, то в якості показника його достовірності можна використовувати величину $\gamma=U / N, \gamma \in[0,1]$, де $U$ - оцінка рівня кваліфікації оператора.

Так як лінгвістичні значення оцінок кількісних ознак формалізовані у вигляді нечітких LRінтервалів 3 функцією розподілу повноважень $\pi_{A_{i}}(x)=\langle\alpha, \underline{m}, \bar{m}, \beta\rangle_{L R}$, то 3 урахуванням ступеня довіри до оператора $\gamma$ в якості розглянутих обмежень приймемо наступні співвідношення:

$$
\begin{aligned}
& \alpha^{*}= \begin{cases}\frac{\alpha}{\gamma}, & \frac{\alpha}{\gamma} \leq \underline{m}-x_{\min }, \\
\left(\underline{m}-x_{\min }\right) \gamma, \frac{\alpha}{\gamma}>\underline{m}-x_{\min } ;\end{cases} \\
& \beta^{*}= \begin{cases}\frac{\beta}{\gamma}, & \frac{\beta}{\gamma} \leq x_{\max }-\bar{m}, \\
\left(x_{\max }-\bar{m}\right) \gamma, \frac{\beta}{\gamma}>x_{\max }-\bar{m} ;\end{cases}
\end{aligned}
$$

$$
\begin{aligned}
& \underline{m}^{*}= \begin{cases}\underline{m}, & \frac{\alpha}{\gamma} \leq \underline{m}-x_{\min }, \\
x_{\min }+\left(\underline{m}-x_{\min }\right) \gamma, & \frac{\alpha}{\gamma}>\underline{m}-x_{\min } ;\end{cases} \\
& \bar{m}^{*}= \begin{cases}\bar{m}, & \frac{\beta}{\gamma} \leq x_{\max }-\bar{m}, \\
x_{\max }-\left(x_{\max }-\bar{m}\right) \gamma, & \frac{\beta}{\gamma}>x_{\max }-\bar{m},\end{cases}
\end{aligned}
$$

де $\Theta^{*}$ - модифіковані відповідно до значення ступеня довіри до джерела інформації параметри нечіткого LR-інтервалу, $x_{\min }, x_{\max }$ - допустимий інтервал зміни значень ознаки $X$. Для якісних ознак, формалізованих у вигляді розподілів можливостей класів алфавітів, у якості розглянутих обмежень приймемо вираз:

$$
\pi^{*}\left(K_{i}\right)=\sup \left(\pi\left(K_{i}\right), 1-\gamma\right),
$$

де $\pi\left(K_{i}\right)$ - можливість класу $K_{i}$.

Абсолютно недостовірні дані $\gamma \rightarrow 0$ еквівалентні тривіальним твердженням:

$$
\begin{aligned}
& \forall x \in A_{i}, \pi_{A_{i}}^{*}(x) \rightarrow 1 ; \\
& \forall K_{i}, \pi^{*}\left(K_{i}\right) \rightarrow 1 .
\end{aligned}
$$

Для абсолютно достовірних даних $\gamma \rightarrow 1$, Отримуємо повну відповідність експертних знань про інтерпретацію лінгвістичної оцінки значення відповідної ознаки:

$$
\pi_{A_{i}}^{*}(x)=\pi_{A_{i}}(x) ; \quad \pi^{*}\left(K_{i}\right)=\pi\left(K_{i}\right) .
$$

Запропонований метод дозволяє врахувати зростання неточності оцінок значень ознак, що надходять від джерел інформації з нестохастичною невизначеністю, при зниженні їх достовірності.

Як зазначалося вище, при обробці результатів спостережень повинна бути сформована узагальнена характеристика прояви ознак повітряних об'єктів. В результаті узагальнення даних про ознаки повітряних об'єктів повинні бути отримані характеристики законів розподілу значень ознак за інтервал спостереження.

Узагальнені за інтервал спостереження характеристики значень ознак будуть в подальшому використані в якості вихідних даних для розпізнавання повітряних об’єктів. Розглянемо далі стисло зміст пропонованого методу узагальнення даних про значеннях кількісних $\mathrm{i}$ якісних ознак повітряних об’єктів.

Оскільки в якості формалізму для подання апріорних і поточних даних про значеннях кількісних ознак обрані нечіткі LR-інтервали, узагальнена характеристика значень ознак за період спостереження 
повинна бути також представлена у вигляді нечіткого LR-інтервалу [6].

Узагальнення результатів спостереження якісних ознак має проводитися з урахуванням можливості реєстрації даних ознак системою різнотипних джерел $з$ відмінними в суміжних циклах оновлення інформації значеннями. При цьому, кожне отримане значення має вносити свій “внесок” в узагальнене розподіл заходів невизначеності класів алфавіту якісної ознаки. Оскільки значення якісних ознак формалізуються у вигляді розподілів можливостей класів алфавітів, то і узагальнена характеристика значень якісних ознак повинна бути представлена у вигляді розподілу можливостей [6-7].

В якості рекурентного правила узагальнення результатів спостереження значень якісних ознак, представлених у вигляді відповідних алфавітів класів, приймемо вираз:

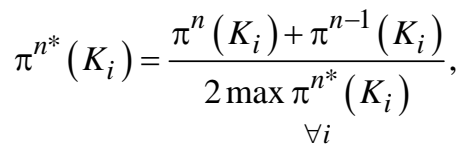

де $i=1, \ldots, I, I-$ кількість класів алфавіту, відповідного якісному ознакою;

$$
\pi^{n-1}\left(K_{i}\right), \pi^{n}\left(K_{i}\right), \pi^{n^{*}}\left(K_{i}\right)-\text { значення заходи }
$$

можливості $i$-го класу, отримані в результаті узагальнення за $n-1$ циклів оновлення інформації, в $n$-му циклі і в результаті узагальнення за $n$ циклів відповідно.

Таким чином, при узагальненні результатів спостереження повітряних об'єктів формується опис ознак об'єкту у вигляді параметрів законів розподілів їх значень. При цьому використовуються результати узагальнення, отримані в попередніх циклах оновлення інформації і поточні оцінки значень ознак. Коректність використовуваних правил підтверджується тим, що результати узагальнення задовольняють аксіомам нечітких заходів, використовуваних при формалізації значень ознак. Отримані узагальнені розподіли значень ознак будуть використовуватися в якості вихідних даних для вирішення завдання розпізнавання повітряних об'єктів [8].

\section{2. Методика розв'язання задачі розпізнавання повітряних об'єктів в умовах різнорідності неповноти і надмірності даних про ознаки}

Всі апріорні розподіли ознак (далі просто ознаки) за ступенем їх апріорної інформативності для розпізнавання об'єктів можна розділити на істотні (прямі) і несуттєві (непрямі).

Пропонується формалізований опис процесу розпізнавання здійснювати у вигляді ієрархічної функціональної мережі. Функціональна мережа - це орієнтований граф, складений з названих дуг і вершин. Дуги графа відображають той факт, що верши- на, 3 якої виходить дуга, є аргументом вершини, в яку вона входить. Опис вершин мережі задає процедуру отримання результату за значеннями аргументів, пов’язаних входять дугами з даної вершиною.

При вирішенні поставленого завдання розпізнавання будемо використовувати наступні типи вершин:

1. Початкові вершини мережі - апріорні і поточні розподілу значень ознак, представлені для кількісних ознак нечітким LR-інтервалом, для якісних розподілом повноважень класів, які відповідають даним ознаками.

2. Вершини розрахунку ступеня істинності різнорідних ознак.

3. Вершини операції кон'юнкції ознак опису класу (кон'юнктивні вершини) - функції ТА-згортки приватних значень ступеня істинності.

4. Вершини, відповідні операції диз’юнкції ознак (наборів ознак) опису класу (диз'юнктивні вершини) - це функції АБО-згортки приватних значень ступеня істинності.

5. Вершини, відповідні операції доповнення ознак опису класу.

6. Вершина нормування розподілу повноважень класів алфавіту. В процесі пошуку рішення розрахунок ступеня істинності класів алфавіту проводиться незалежно один від одного. Для подальшого коректного використання цієї інформації у випадках:

- розпізнавання в алфавіті наступного рівня ієpapxiï;

- об’єднання 3 незалежними результатами розпізнавання;

- прийняття остаточного рішення про клас повітряного об’єкту, необхідно, щоб вихідні розподілом алфавіту було також розподіл повноважень. Для цього вводиться розглянута вершина з відповідною їй функцією.

7. Вершини об'єднання розподілів, отриманих в результаті незалежного розпізнавання в співпадаючих алфавітах. Для розглянутої операції характерна різнорідність об’єднуються розподілів.

Один $з$ відомих підходів до об'єднання незалежних розподілів заснований на використанні правила Демпстера [9-10].

8. Цільова вершина мережі, яка реалізує вбрання правило прийняття рішення про клас спостережуваного ПО. Як правила прийняття рішення про клас об'єкту може бути прийнято правило максимальної апостеріорної можливості класів, що враховує нечітку класифікацію повітряних об’єктів.

В якості формалізованого опису процесу розпізнавання обраний граф ієрархічної функціональної мережі, що відбиває склад і зміст основних етапів процесу розпізнавання. Аналіз відносин між вершинами обраної мережі свідчить про приналежність іiі 
до класу однорідних ФС. Використання адресному матриці суміжності для формалізації відносин між вершинами мережі на рівні програмних модулів дозволяє значно скоротити час пошуку рішення про клас об'єкта, що спостерігається і реалізувати процес розпізнавання в реальному масштабі часу.

В якості основи для об'єднання результатів розпізнавання незалежних джерел прийнято правило Демпстера [9]. Для об’єднання неузгоджених розподілів можливостей запропоновано використовувати попереднє перетворення одного з поєднуваних розподілів до відповідного йому розподілу ймовірностей. У разі, коли значення ступеня неузгодженості об'єднуються розподілів перевищує заданий поріг, як результуючий приймається найбільш достовірне 3 них. Граничне значення ступеня неузгодженості об’єднуються розподілів вибирається з урахуванням характеристик достовірності.

$$
m_{12}\left(E_{k}\right)=\frac{\sum_{E_{i} \bigcap E_{j}=E_{k}} m_{1}\left(E_{i}\right) m_{2}\left(E_{j}\right)}{1-m_{o}} .
$$

\section{Висновки}

Удосконалена методика формалізації структур даних про ознаки повітряних об'єктів враховує характеристики точності і достовірності джерел інформації з нестохастичною невизначеністю і рекурентними правилами узагальнення оцінок значень ознак при багаторазовому спостереженні.

Це дозволяє врахувати вплив характеристик джерел інформації на результати розпізнавання i здійснювати розпізнавання не за окремими фрагментами проявів ознак об'єктів, а по їх узагальненої сукупності, що підвищує достовірність прийнятих рішень.
Розроблений метод формалізації процесу розпізнавання повітряних об’єктів на основі описів класів різнорідними ознаками, відрізняється від відомих використанням ієрархічної функціональної мережі.

Удосконалення методу об'єднання незалежних результатів розпізнавання на основі правила Демпстера полягає в попередньому перетворенні одного 3 неузгоджених розподілів можливостей класів алфавіту в розподіл ймовірностей. Це дозволяє проводити коректне об'єднання неузгоджених розподілів можливостей класів алфавіту з використанням правила Демпстера.

Проведено дослідження застосовності розробленого правила при об’єднанні неузгоджених розподілів ймовірностей класів алфавіту. В результаті проведеного дослідження побудовано сімейство кривих, що дозволяє визначити порогове значення ступеня неузгодженості об'єднуються розподілів за даними про достовірність джерел інформації. У разі перевищення значенням ступеня неузгодженості порогового, як результуючий приймається розподіл від найбільш достовірного джерела.

Розроблений метод пошуку рішень про класи розпізнаваних об'єктів на графі функціональної мережі відрізняється від відомих розробленим способом отримання інтервального оцінки ступеня істинності класів в умовах відсутності даних щодо окремих ознак ПО і запропонованим евристичним правилом, що дозволяє скоротити розмірність безлічі вершин мережі, які перебираються при пошуку рішення про клас ПО. Метод дозволяє проводити пошук рішень про класи ПО в умовах неповноти і надмірності даних про ознаки.

\section{Список літератури}

1. Russel S. Artificial intelligence. A modern approach, $3^{\text {rd }}$ Edition / S. Russel, P. Norvig. - Tulsa: Williams, 2011. $-1410 \mathrm{p}$.

2. Oxman S. White paper: adaptive learning systems [Електронний ресурс] / S. Oxman, W. Wong // DV X Innovations DeVry Education Group. $\quad-\quad 2014 . \quad-\quad 20$ P. $1-30 . \quad$ - $\quad$ Режим доступу: https://kenanaonline.com/files/0100/100321/DVx_Adaptive_Learning_White_Paper.pdf.

3. George F.L. Artificial Intelligence: Structures and Strategies for Complex Problem-Solving / F.L. George. - Tulsa: Williams, 2005. $-864 \mathrm{p}$.

4. Яхъяева Г.Э. Нечеткие множества и нейронные сети / Г.Э. Яхъяева. - М.: Интернет-университет информационных технологий, Бином, 2011. - 320 с.

5. Горелик А.Л. Методы распознавания / А.Л. Горелик, В.А. Скрипкин. - М.: Высш. шк, 2004. - 261 с.

6. Гафаров Е.Р. Графический метод решения задач комбинаторной оптимизации / Е.Р. Гафаров // Автоматика и Телемеханика. - 2016. - № 12. - С. 26-36.

7. Журавлев Ю.И. Об алгебраическом подходе к решению задач распознавания или классификации / Ю.И. Журавлев // Проблемы кибернетики. - 2005. - № 33. - С. 5-68.

8. Dempster A. The Dempster-Shafer calculus for statisticians / A. Dempster // International Journal of Advanced Research. - 2008. - Vol. 48. - P. 365-377.

9. Dezert J. On the behavior of Dempster's rule of combination, School on Belief Functions Theory and Applications [Електронний ресурс] / J. Dezert, A. Tchamova. - Режим доступу: http://hal. Archives-ouvertes. Fr/hal-00577983/.

10. Dezert J. On the mathematical theory of evidence and Dempster's rule of combination [Електронний ресурс] / J. Dezert, A. Tchamova, F. Dambreville. - Режим доступу: http://hal. Archives-ouvertes. Fr/hal-00591633/fr/. 


\section{References}

1. Russel, S. and Norvig, P. (2011), Artificial intelligence. A modern approach, Williams, Tulsa, 1410 p.

2. Oxman, S. and Wong, W. (2014), White paper: adaptive learning systems, DV X Innovations DeVry Education Group, pp. 1-30, available at: www.kenanaonline.com/files/0100/100321/DVx_Adaptive_Learning_White_Paper.pdf.

3. George, F.L. (2005), Artificial Intelligence: Structures and Strategies for Complex Problem-Solving. Williams, Tulsa, 864 p.

4. Yakhyeva, G.E. (2011), “Nechetkie mnozhestva I neironnye seti” [Fuzzy sets and neural networks], Internet-universitet Informatsionnykh Tekhnologii, Binom, Moscow, 320 p.

5. Gorelik, A.L. and Skripkin, V.A. (2004),"Metodyi raspoznavaniya” [Recognition methods], Vyissha Shkola, Moscow, $261 \mathrm{p}$.

6. Gafarov, E.R. (2016), “Graficheskii metod resheniya zadach kombinatornoi optimizatsii” [Graphic method for solving combinatorial optimization problems], Automation and Telemechanics, No. 12, pp. 26-36.

7. Zhuravlev, Yu.I. (2005), “Ob algebraicheskom podhode k resheniyu zadach raspoznavaniya ili klassifikatsii” [On the algebraic approach to solving recognition or classification problems], Cybernetics Problems, Vol. 33, pp. 5-68.

8. Dempster, A. (2008), The Dempster-Shafer calculus for statisticians, International Journal of Advanced Research, Vol. 48, pp. 365-377.

9. Dezert, J. and Tchamova, A. (2011), On the behavior of Dempster's rule of combination, School on Belief Functions Theory and Applications, 4-8 April 2011, Autrans, France, available at: www.hal. Archives-ouvertes. Fr/hal-00577983/.

10. Dezert, J., Tchamova, A. and Dambreville, F. (2011), On the mathematical theory of evidence and Dempster's rule of combination, available at: www.hal. Archives-ouvertes. Fr/hal-00591633/fr/.

\section{Відомості про авторів:}

\section{Тимочко Олександр Іванович} доктор технічних наук професор професор кафедри

Харківського національного університету

Повітряних Сил ім. І. Кожедуба, Харків, Україна https://orcid.org/0000-0002-4154-7876

\section{Дубовик Геннадій Валентинович} слухач

Національної академії оборони

України ім. І. Черняховського

Київ, Україна

https://orcid.org/0000-0003-2961-237X

Мажаров Володимир Сергійович

кандидат технічних наук

викладач

Льотної академії Національного

авіаційного університету

Кропивницький, Україна

https://orcid.org/0000-0002-9535-0841
Information about the authors:

\section{Oleksandr Tymochko}

Doctor of Technical Sciences Professor

Professor of Department

of Ivan Kozhedub Kharkiv

National Air Force University,

Kharkiv, Ukraine

https://orcid.org/0000-0002-4154-7876

\section{Gennadiy Dubovyk}

Student

of Ivan Chernyakhovsky National

Defense University of Ukraine,

Kyiv, Ukraine

https://orcid.org/0000-0003-2961-237X

\section{Volodymyr Mazharov}

Candidate of Technical Sciences

Instructor

of the National Aviation University

"Flight Academy of the National Aviation University",

Kropyvnytskyy, Ukraine

https://orcid.org/0000-0002-9535-0841

\section{МЕТОД ФОРМАЛИЗАЦИИ ДАННЫХ ПРИ РЕШЕНИИ ЗАДАЧ РАСПОЗНАВАНИЯ ВОЗДУШНЫХ ОБЪЕКТОВ}

А.И. Тимочко, Г.В. Дубовик, В.С. Мажаров

В работе разработана методика формализации структур данных признаков воздушных объектов, которая учитывает характеристики точности и достоверности источников информачии с нестохастической неопределенностью и рекуррентными правилами обобщения оценок значений признаков при многократном наблюдении воздушных объектов. В основу разработанной методики были положены методы формализации процесса распознавания, оценки степени истинности разнородных признаков, объединения независимых результатов распознавания, поиска решений о классах распознаваемых воздушных объектов с учетом неполноты и избыточности данных о признаках. Разработанный метод формализации процесса распознавания воздушных объектов на основе описаний классов разнородными признаками отличается от известных использованием иерархической функииональной сети. Совершенствование метода объединения независимых результатов распознавания на основе правила Демпстера заключается в предварительном преобразовании одного из несогласованных распределений возможностей классов алфавита в распределение вероятностей. Это 
позволяет проводить корректное объединение несогласованных распределений возможностей классов алфавита с использованием правила Демпстера. Проведено исследование применимости разработанного правила при объединении несогласованных распределений вероятностей классов алфавита. Разработанный метод поиска решений о классах распознаваемых объектов на графе функциональной сети отличается от известных разработанныл способом получения интервальной оценки степени истинности классов в условиях отсутствия данных по отдельным признакам воздушных объектов и предложенным эвристическим правилом, что позволяет сократить размерность множества вершин сети, которые перебираются при поиске решения о классе воздушных объектов. Метод позволяет проводить поиск решений о классах воздушных объектов в условиях неполноты и избыточности данных о признаках.

Ключевые слова: формализация данных, признаки воздушных объектов, распознавание, неполнота данных.

\section{TECHNIQUE FOR FORMALIZING DATA \\ IN THE SOLUTION OF TASKS OF RECOGNITION OF AIR OBJECTS}

\section{O. Tymochko, G. Dubovyk, V. Mazharov}

In this work, we developed a method for formalizing the structures of these features of airborne objects, which takes into account the accuracy and reliability characteristics of information sources with non-stochastic uncertainty and recurrent rules for summarizing estimates of the values of attributes during repeated observation of airborne objects. The developed methodology was based on methods of formalizing the recognition process, assessing the degree of truth of heterogeneous features, combining independent recognition results, finding solutions for classes of recognizable air objects, taking into account the incompleteness and redundancy of the data on the features. The developed method of formalizing the process of recognizing airborne objects based on class descriptions by heterogeneous features differs from the known ones by using a hierarchical functional network. The improvement of the method of combining independent recognition results based on the Dempster rule consists in the preliminary transformation of one of the inconsistent distributions of the capabilities of the alphabet classes into a probability distribution. This allows us to correctly combine inconsistent distributions of the capabilities of alphabet classes using the Dempster rule. A study was made of the applicability of the developed rule when combining inconsistent probability distributions of alphabet classes. The developed method for finding solutions for classes of recognizable objects on a functional network graph differs from the known methods for obtaining an interval estimate of the degree of truth of classes in the absence of data on individual features of air objects and the proposed heuristic rule, which allows us to reduce the dimension of the set of network vertices that are sorted when searching for a solution about the class of air objects. The method allows you to search for solutions about classes of airborne objects under conditions of incompleteness and redundancy of feature data.

Keywords: data formalization, signs of airborne objects, recognition, incomplete data. 